\title{
Case Study: A College-Wide Engineering Capstone Experience at the Uni- versity of Tennessee
}

\section{Dr. Jennifer Q Retherford, University of Tennessee, Knoxville}

Dr. Retherford is an alumna of the University of Nebraska, Omaha, and received her graduate degrees from Vanderbilt University. She currently teaches a variety of courses supporting the department of Civil \& Environmental Engineering at the University of Tennessee. Among many structural engineering courses, Dr. Retherford manages the Senior Design Project course for all undergraduate seniors.

\section{Dr. J. A. M. Boulet, University of Tennessee, Knoxville}

J. A. M. (Toby) Boulet has been on the faculty of the University of Tennessee since 1985. He now divides his time equally between teaching and serving as Associate Head for Undergraduate Programs in the Mechanical, Aerospace and Biomedical Engineering department. He has been a member of ASEE since 2004.

Chris Wetteland, University of Tennessee, Knoxville 


\title{
Engagement in Practice: A College-Wide Engineering Capstone Experience at the University of Tennessee
}

\begin{abstract}
The University of Tennessee at Knoxville has developed a pilot study for a college of engineering multi-disciplinary capstone experience, engaging three dedicated college departments to address a design opportunity presented by a local non-profit organization. The College of Engineering at the University of Tennessee was approached by the Friends of the Smokies (Friends) requesting the development of an innovative solution to reduce vandalism of donation boxes located throughout the nearby national park. While the Friends are capable of upgrading and modifying the small structures, the team recognized an opportunity to engage in outreach and solicited assistance from the university with the intention of identifying innovative and unique design concepts to improve the design of the structures. Both the Friends and the Dean of the Tickle College of Engineering recognized the opportunity to immerse students in the design process and a multi-disciplinary team was selected not only to address the community partner needs, but also to pilot a college-wide capstone experience. Management of the project with this new academic experience provides an opportunity to research and share best practices related to such an opportunity. The design project has engaged students and faculty from materials science, mechanical engineering, and civil engineering through an entire academic year experience. While the student design team is challenged with developing a final product that integrates all aspects of their engineering disciplines, the faculty team is also charged with ensuring the students gain a valuable academic experience within this project. To accomplish these objectives, the faculty team has a shared management approach and seeks to identify means and methods to replicate the successful experience in future semesters. The following paper contains a summary of the project shared by the local partner, a brief literature review of similar efforts towards college-wide capstone programs, discussion of the course management approach identified by the faculty, challenges experienced, and a summary of lessons learned.
\end{abstract}

\section{Introduction}

Much research exists in the realm of project-based learning, service-based learning, and active educational environments. Many of these experiences designed by faculty to engage students both within a classroom and with their communities are well contained within a single course. Many complete projects emulating real-world scenarios and conditions are multi-disciplinary in nature. Research also recognizes that most professional services performed by engineers require teams of multi- and inter-disciplinary team members joined through contractual or employment-based relationships. 
With appropriate consideration of the needs of community partners and the pedagogy of projectbased learning, development of a capstone experience at the college level can prove to be an effective means to emulate engineering professional practice. While this ideal is valuable, and partially engrained in the ABET a-k curriculum criteria, implementation of a college of engineering (COE) - wide capstone experience is complex. Curriculum differences, allocation of departmental and college resources, and measurable improvements in student performance are only a few complications that faculty members must resolve in order to develop a successful COEwide capstone experience.

The contents of this paper introduce a brief literature review discussing the existing programs currently working towards the ambitious goal of multi-disciplinary capstone experience, defining "multi-disciplinary" as inclusive of multiple departments within a college of engineering. A summary of the University of Tennessee's on-going COE-wide pilot project is also included, followed by an explanation of the course management approach implemented and observation of engagement with the community partner. The closing will include discussion of the opportunities to replicate the pilot year's success and recommended improvements to the course management approach.

\section{Pilot Project Background}

The opportunity for a pilot college-wide capstone (also referred herein as senior design project) experience was initiated in the spring of 2016 through a solicitation for engineering services by a local non-profit organization. Briefly, the solicitation identified the need for design of a tamperresistant receptacle for use as a donations box in a national park. Ideally, the request came to the University with the intention of developing a donation box design that was innovative and addressed a suite of needs, including ensured security of the donations in the box, tamper-resistant and damage-resistant design, enhancements to payment options, and consideration for replication. The final design developed by the team of students will be shared with local fabricators for installation across the national park. Because the Friends are a current leader in the design of secure donation boxes, the proposed student designs have real opportunity to become a standard in the park system.

Design of the pilot capstone course was completed by three faculty members with the intention to achieve two major goals: (1) develop a COE-wide capstone experience capable of replication in the future and (2) design a course easily integrated across departments within the existing confines of the curriculum of each program. While the project was well suited for multi-disciplinary engineering services, the challenges to a COE-wide capstone experience reside in coordination across curriculum design. To address these two goals, the faculty team identified a flexible management approach to align the existing curriculum needs for each department's capstone 
course. In addition to curriculum awareness, student needs were addressed by involving faculty mentors from each discipline.

\section{Brief Literature Review}

Implementation of the pilot project at University of Tennessee, Knoxville (UTK) reflects findings from previous research on COE-wide capstone programs. Capstone experiences are one of the most comprehensive opportunities to assess student learning in an undergraduate engineering curriculum. Skills across all major assessment criteria for student performance, as defined either by programs or mapped according to the ABET performance criteria, indicate that capstone courses are aptly named and considered a significant experience for students within all engineering programs. A thorough evaluation of assessment within capstone courses through a nation-wide study by McKenzie, et al. identified a few key findings relevant to the discussion of capstone experiences, regardless of the type of engineering discipline. Most notably an overwhelming majority of faculty members consider the capstone experience to be a critical aspect of the undergraduate curriculum and that ABET Criterion 3 (often casually referred to as criteria $a-k$ ) are pair well with the objectives of the diverse capstone experiences of the nearly 100 faculty members surveyed ${ }^{1}$.

Considering ABET Criterion 3 as a major driving force in the development, design, and continual improvement tool for design of senior design courses, focus on student outcome (d) is a valuable metric. The outcome requests that graduates of accredited undergraduate engineering programs develop "an ability to function on multidisciplinary teams”2. Successful participation on a multidisciplinary team can be considered a valuable opportunity for which engineering programs should consider developing for today's graduates. A thought-provoking study performed by Miller and Olds obtained survey feedback from industrial design teams and $75 \%$ of the companies and agencies confirmed that their design teams were comprised of multiple disciplines ${ }^{3}$. Results from a study at Georgia Tech indicated that students participating in multidisciplinary capstone design courses performed better in realms of innovation and problem-solving, developed stronger "soft skills" related to communication, and were more successful in finding employment after graduation ${ }^{4}$.

The partnership between the Friends and UTK was modeled with the intention to provide students an opportunity to develop a cohesive design group innately. The faculty members idealized the college-wide project as a group of students who would gather to 'get the job done', without necessarily defining the roles and responsibilities of each specific discipline. This aligns with the concept that professional design teams are often formed by coupling a series of different firms with the necessary expertise through a contractual relationship. The faculty assumed that students would gravitate to the work that was "theirs" and support the broad needs of the project that might not be directly related to their engineering discipline. Then, the development of 'soft skills' would 
naturally grow as communication, time management, and delegation of work would grow in response to the project needs.

\section{COE Capstone Course Management Approach}

While multi-disciplinary projects are considered valuable educational experiences, and are even considered pivotal in emulating real-world design circumstances, implementation of a collegewide capstone program is challenging. To overcome the challenges of a truly integrated design experience, this pilot program facilitated a multi-disciplinary design experience through a flexible management system. More specifically, three issues were resolved prior to the start of the project: curriculum matching, deliverables, and management of expectations. First, the students were integrated into a yearlong (2 semester) senior design experience, regardless of their program's traditional curriculum format. This was easily accommodated through self-driven students who were motivated to participate by their interest in the project. Civil engineering (CEE) and Materials Science (MSc) students were permitted to earn a "technical elective" credit for their participation in the semester prior to their senior design course enrollment as a means to provide academic credit for their work on the project while mechanical engineering (MABE) students enrolled in their required senior design project coursework. While this format would be suitable for any number or type of engineering disciplines, the selection of these three disciplines was made on a volunteer basis with faculty identifying the match of the project to their engineering realm. Secondly, identification of a common deliverable for the team integrated the needs presented for each discipline's senior design project course. Each discipline had requirements related to format and content; however, as one might expect, the needs of the project paired well with the needs identified by all faculty. The student team was held accountable to deliver according to their course instructions, with the team report presenting calculations and drawings satisfying all discipline requirements. Lastly, the project expectations were driven according to partner needs rather than academic expectations. The partner was informed of the experimental nature of the multidisciplinary team format and was asked to address the entire team as they would a professional partner. With this understanding, the team's approach to the needs of the partner modeled well across all disciplines.

Multi-disciplinary capstone courses engaging students across various college of engineering disciplines requires a management approach cognizant of the need for appropriate management of college resources, driven by project expectations and deliverables. To address the balance of discipline-specific needs, the faculty team identified a project plan with flexibility and the management approach can be summarized as:

- $\quad$ Each faculty member serves as an equal manager of the project.

- Each faculty maintains the ABET and departmental standards required for their represented department. 
- Students were tasked as the major drivers of the project. Limited restrictions were applied to their engagement across team disciplines.

The benefits of a management role by a faculty member from each discipline outweigh the contrary. The necessary role of the faculty member is to serve as a mentor, facilitator, or manager for the capstone project. In order to achieve this successfully, the faculty member must be integrated and a regular participant in the design project. In the spirit of the ASCE Code of Ethics, those mentors must serve in the area of their professional competence; thereby requiring that each multi-disciplinary design experience involve an engineer of a related field. While it might be assumed that multiple professors assigned to a single senior design project may be redundant, this model matches professional practice as each discipline would approach the contractual relationship aware of not only the hierarchy within the design team, but also branched into the paired design firms.

In addition to adhering to ethical practice of serving in the engineering realm of expertise, the multi-disciplinary capstone format benefits from inclusion of a faculty mentor from each engaged engineering discipline. As curriculum for the capstone courses vary across disciplines, the faculty member for the department can then be responsible for management of departmental obligations, such as course lectures, intermediate submittals, and non-project related activities. Faculty representation from each discipline of student work is important in ensuring that all students graduating from the separate programs abide by all department-specific and ABET-related requirements.

Lastly, the philosophy that the students will drive the project to innovation and success was an idealistic approach to management of the project. This pilot observed the team's ability to selfmotivate. Team members appeared to identify their strengths within the team dynamic, and each individual appeared to contribute as a complementary member of the team. This approach further enhances the multi-disciplinary approach as students are immersed in an experience that most closely emulates the engineering profession.

\section{Community Partner Engagement Observations}

The college-wide capstone experience was intended as a pilot program internally for the college, but was focused on delivering a successful project to the Friends. To ensure a successful experience, engagement with the partner was satisfied through a client-based project partnership and course requirements for a series of interactive meetings. In the first semester, the MABE course required a series of meetings, including a kick-off meeting, a mid-term meeting, and a meeting at the end of the term. The objectives of these meetings began with understanding the full scope of work requested by the community partner, transitioned to discussion of schematic design concepts, and concluded with a summary of the developed design solution. At each periodic 
meeting, the community partner was provided an opportunity to confirm that the design met their needs. Through the final semester of the project, a series of meetings were held on a monthly basis to share the progress in creation of a prototype for the design. To abide by the requirements of all disciplines, intermediate actions included experimental materials testing and engineering computational work, for which students shared their means and methods with the Friends.

Ultimately, the community partner received a design solution to the proposed project, but likely received additional engineering services not originally intended. To adhere to requirements in the Materials Science department to perform materials testing, the Friends received testing data that they may not have otherwise requested. Similar elements of the final design documentation, such as the engineering calculations to size a structural pier and foundation for the donation box, also include content that the community partner would not have requested in a paid design contract. However, recognizing their involvement in an academic experience, this did not seem to detract or deter the community partner.

\section{Closing Remarks \& Lessons Learned}

Development of a college-wide capstone design experience is increasingly important, as practical engineering projects require integrated design solutions. In an attempt to address complexities related to departmental differences, each discipline was represented by a professor mentor. Future work is necessary to develop quantitative and qualitative assessment metrics in comparison to performance of other students and in response to other community partner expectations. However, the current anecdotal discussions indicate that the college-wide experience was a valuable experience requiring no additional support beyond traditional capstone coursework.

A few valuable lessons were learned during the yearlong pilot project. First, students were challenged with an informal management scheme within the student team. While the faculty team initially believed in a student-driven process for which leaders would rise to the occasion, the student team did not develop a hierarchy. Rather, some students took on leadership roles when time was convenient, but quickly released themselves from the role when other priorities such as travel for job interviews and other academic activities took time from their schedules. Second, the design project's basic engineering requirements were a surprising challenge for delegation of work. Initially, it was assumed that this project was well suited for interdisciplinary work because of its relatively simple needs. However, because the work did not fall into one of the 'silos' of a specific department, students did not immediately take work upon themselves. The students tended to gravitate towards work they recognized as 'theirs', but did not pick up the generic work. For example, civil engineering students performed the foundation design in a timely manner, but drafting was not performed until faculty mentors pursued the need of the work to be completed. Lastly, the students struggled in the transition from informal to formal course structures. In order to comply with departmental curriculum, students in CEE and MSc enrolled in independent study 
courses for their first term and then enrolled in the department's senior design project course for their second term, unlike the students in the MABE department's yearlong, two semester, capstone courses. The student team was driven to abide by the structure of the MABE course structure and course syllabus and transitioning to the "new" requirements in the second semester was slow.

The faculty members are excited to participate in a second project to implement a few changes in the management of the college-wide capstone experience. The faculty members recognize a few successes of the pilot program and suggest the following modifications:

Successful aspects:

1. A faculty member from each discipline must be engaged in the project, formally, as an instructor of record for the senior design project course.

2. The students genuinely appreciated the opportunity to work across disciplines, with the understanding that the experience would likely be reflected in their future professional lives.

3. The boundaries of college requirements can be overcome relatively easily. Through independent study courses and the dedication of faculty mentors, the curriculum needs for each department were a minimal concern at any time during the yearlong duration.

Intended improvements:

1. Delegation of student roles and responsibilities is important. A recommendation is to integrate project management as a necessary component of the course. Formally assigning tasks, ideally by the students rather than delegated by faculty, should improve the time management of each individual student and ensure all students are involved throughout the project.

2. A structured and well-defined transition would be valuable to students moving from an independent study semester to a formal senior design project course term. A deliberate mid-project meeting to discuss the course requirements at the change of the semester should improve the immediate understanding of the necessary deliverables for the discipline-specific courses. A written contract or supplemental course syllabus is considered a valuable document to share with the students.

3. Similar to management at the student level, a single dedicated faculty lead would likely improve the likelihood of success of the project and courses. With the demands of research and other faculty obligations, it may be convenient for a faculty member to become dis-engaged. Similar to the roles of the students, a deliberate definition of this role clarifies the chain of command for both the faculty and students involved.

\section{References}


1. McKenzie, L. J., Trevisan, M. S., Davis, D. C. \& Beyerlein, S. W. Capstone design courses and assessment: A national study. in Proceedings of the 2004 American Society of Engineering Education Annual Conference \& Exposition 1-14 (2004).

2. ABET Board of Delegates. Criteria for Accrediting Engineering Programs. (2015).

3. Miller, R. L. \& Olds, B. M. A model curriculum for a capstone course in multidisciplinary engineering design. J. Eng. Educ. 83, 311-316 (1994).

4. Hotaling, N., Fasse, B. B., Bost, L. F., Herman, C. D. \& Forest, C. R. A quantitative analysis of the effects of a multidisciplinary engineering capstone design course. J. Eng. Educ. 101, 630 (2012). 